\title{
Effects of Health Insurance on Perceived Quality of Care Among Latinos in the United States
}

\author{
Debra Perez, $P h D^{7}$, Alfonso Ang, $P h D^{2}$, and William A. Vega, $P h D^{2}$ \\ ${ }^{1}$ Robert Wood Johnson Foundation, Princeton, NJ, USA; ${ }^{2}$ UCLA Department of Family Medicine, Los Angeles, CA, USA.
}

\begin{abstract}
BACKGROUND: There is suggestive evidence that lower rates of health insurance coverage increases the gaps in quality and access to care among Latinos as compared with non-Latino whites. In order to examine these potential disparities, we assessed the effects of insurance coverage and multiple covariates on perceived quality of care.
\end{abstract}

OBJECTIVE: To assess the distribution of perceived quality of care received in a national Latino population sample, and the role of insurance in different patient subgroups.

DESIGN: Telephone interviews conducted between 2007 and 2008 using the Pew Hispanic Center/Robert Wood Johnson Foundation Latino Health Surveys (Waves 1 and 2).

PARTICIPANTS: Randomly selected Latino adults aged $\geq 18$ years living in the United States.

MEASUREMENTS: Pearson $\chi^{2}$ tests identified associations among various demographic variables by quality of care ratings (poor, fair, good, excellent) for the insured and uninsured (Wave 1: $N=3545$ ). Subgroup analyses were conducted among Wave 2 participants reporting chronic conditions $(N=1067)$. Bivariate and multivariate analyses were conducted to estimate the effects of insurance, demographic variables and consumer characteristics on quality of care.

RESULTS: Insurance availability had an odds ratio of 1.47 (95\% CI, 1.22-1.76) net of confounders in predicting perceived quality of care among Latinos. The largest gap in rates of excellent/good ratings occurred among the insured with eight or more doctor visits compared to the uninsured $(76.2 \%$ vs. $54.6 \%, P<.05)$.

CONCLUSIONS: Future research can gain additional insights by examining the impact of health insurance on processes of care with a refined focus on specific transactions between consumers and providers' support staff and physicians guided by the principles of patient-centered care.

KEY WORDS: insurance; Latinos; quality; acculturation; chronic care. J Gen Intern Med 24(Suppl 3):555-60

DOI: $10.1007 / \mathrm{s} 11606-009-1080-\mathrm{z}$

(C) Society of General Internal Medicine 2009

\section{INTRODUCTION}

This study examines the effects of insurance on perceptions of quality of care received using a national Latino population sample. Over one third of US Latinos do not have health insurance which likely affects both health care access and quality of care. ${ }^{1}$ Presumably consumers are more likely to perceive a lower quality of care if they are frustrated and experience inadequate care due their inability to cover medical care costs, or if they have other pressing financial obligations that must be set aside to cover these costs. ${ }^{2}$ No insurance impedes choices in providers, hampers continuity of care including access to specialty providers, and contributes to inconsistent medication adherence. ${ }^{1,3}$ With fewer resources, there are fewer choices: an unsatisfactory provider must be tolerated or health care is delayed or not received. ${ }^{4}$ A 2008 survey from the Pew Latino Center reported that $42 \%$ of uninsured Latino adults lacked a usual health care provider and, among the insured, $19 \%$ were estimated to lack a health care provider. In addition, the groups least likely to have a usual health care provider were men (36\%), the young (37\% of those aged 18-29 years), the less educated (32\% of those lacking a high school diploma) and foreign born (30\%). ${ }^{5}$

Why do we care about perceptions of quality? Perceptions of quality have been increasingly accepted as valid and important measures of health care quality ${ }^{1,6}$. Furthermore, perceptions of quality have been associated with poor health outcomes. ${ }^{6,7}$ Previous studies with few exceptions ${ }^{1}$ tend to focus on difference in quality among majority groups. The 2007 National Healthcare Quality and Disparities Report from the Agency of Healthcare Research Quality documented minimal progress in overcoming a broad range of health care quality problems among US ethnic minorities. Among other findings, the report showed Latino adults reported having communication problems with their providers. ${ }^{8}$ Other studies of ethnic minority groups showed that disparities in quality could be ameliorated by increased access to insurance. ${ }^{1}$ For most quality and access measures, Latinos demonstrated worse outcomes compared to the quality and access to care that non-Latino Whites experienced. And, in most cases the quality gap was increasing for Latinos. Differences in perceived quality have been previously documented between insured and uninsured White nonLatino patients. $^{9}$

Most peer-reviewed literature on quality of care has focused on estimates and inferences for the general Latino population with few studies looking at internal variability among Latinos. ${ }^{1}$ Studies such as these assume homogeneity of Latinos, despite evidence of important historic, regional, socio-economic, and cultural differences among subgroups. A substantial body of published services research has demonstrated a link between 
these determinants and Latino subgroup access to care and types of providers utilized to address health problems. ${ }^{10,11}$

The diversity of the Latino population, along with its unique characteristics such as a majority being foreign born, low education and income statuses, and having variable English language proficiency, are important determinants in understanding disparities in the quality of health care among Latinos. ${ }^{5}$ However, these characteristics are not equally shared among Latinos of different national origins. ${ }^{3}$ For instance, $29 \%$ of Latinos lacking a usual source of health care are of Mexican origin, while only $16 \%$ are of Puerto Rican origin, suggesting the important role of citizenship in receipt of health care, especially as it relates to eligibility for public insurance among low income people. ${ }^{5}$

Health care disparities are widespread for Latinos and other ethnic minority groups. ${ }^{1}$ Quality of care (QOC) is defined by the Institute of Medicine as the degree to which health services increase the likelihood of desired health outcomes and are consistent with current professional knowledge. ${ }^{12}$ QOC is frequently described as having technical processes (tests, treatments) and interpersonal processes (social-psychological aspects of the patient-physician interaction such as communication, friendliness, explanations, and being caring and sensitive to patients' needs). While there is much evidence on ethnic disparities in access to care, there is less research on disparities in interpersonal processes of care experienced by Latino and other ethnic minority patients. ${ }^{13}$

The topic is conceptually complex. For this paper, an important aspect of our definition of quality of care is the interpersonal processes of care that are patient-centered, and subjectively assessed by the patients themselves. This definition, perceived quality of care, assumes that treatment providers acknowledge patients' cultural beliefs and preferences, and recognize that fidelity of communication is fundamental to patient satisfaction and perceived quality of care received. Improved interpersonal processes presumably improve patient outcomes through better treatment adherence, improved knowledge of health conditions, and greater motivation and ability to manage their chronic illnesses and other health problems.

We propose to examine several understudied research questions regarding determinants of perceptions of quality of care among Latinos. First, what is the distribution of perceived quality of care ratings among Latinos in different demographic subgroups, and how is this distribution affected by insurance availability? Second, how is perceived quality of care distributed among Latinos with specific chronic diseases? Third, how is intensity of treatment utilization (as indicated by frequency of doctor visits) associated with insurance and perceptions of quality of care? Fourth, what factors are most influential in predicting perceived quality of care for Latinos in a controlled model?

\section{METHODS}

The study data comes from the recent Pew Hispanic Center/ Robert Wood Johnson Foundation Latino Health Surveys (Wave 1 and 2), ${ }^{14}$ conducted using a nationally representative sampling frame of randomly selected Latino adult participants aged $\geq 18$ years, residing in the United States. The Wave 2 survey was the primary source of data for this study. Data were collected during the spring 2008, as a follow-up subsample of the original Wave 1 survey $(N=4013)$ collected in 2007. Whereas Wave 1 provided a wide scan of demographics, health status, beliefs and behaviors, and health care utilization indices, Wave $2(N=1067)$ focused primarily on chronic disease quality of care, patient activation and children's health care. All interviews were conducted using the Computer Assisted Telephone Interviewing (CATI) system. The survey data were weighted using a two-stage weighting design to ensure an accurate representation of the national Latino population. In order to control for unobservable heterogeneity and adjust for correlation of the error terms among survey participants 'clustered' within the same geographic regional areas (i.e., Midwest, Northeast, South and Western regions of the US), we used fixed effects model in the regression analysis.

Wave 1 and 2 surveys included questions regarding access to care, ratings of health care received in the past year, health insurance coverage, chronic conditions, number of doctor visits, country of origin, and immigration status of the survey respondents. We used these responses to examine the quality of care received for the insured and the uninsured.

To examine the heterogeneity across different subgroups, we used a series of questions to determine the immigration status of the survey participants. Participants were first asked whether they were born in the United States. If they were not born in the United States, they were asked whether they were US citizens. If they were not citizens, participants were asked if they were legal permanent residents of the United States. From these series of questions, we classified Latinos into four categories: US-born citizens, foreign-born citizens, legal foreign-born permanent residents, and undocumented residents. We also examined the perceived quality of care ratings for different subgroups by country of origin.

\section{Statistical Analysis}

We examined the associations among the various demographic variables by perceived quality of care ratings for the insured and uninsured, using the Rao-Scott adjustment to the Pearson $\chi 2$ statistic. $^{15}$ A subgroup analysis was conducted among those who responded to questions on chronic conditions ( $n=$ 1067). We analyzed the associations among these chronic conditions (i.e., diabetes, asthma, hypertension, etc.) and the quality of care ratings using the Rao-Scott adjustment to the Pearson $\times 2$ statistic. We also examined the number of visits for the insured and uninsured and the corresponding quality of care ratings among those who had one visit in comparison to those with multiple visits. We used weighted ordered logistic regression to examine the perceived quality of care outcome controlling for age, sex, education, marital status, insurance status, chronic conditions, country of origin, age of arrival and region of the country. The score test ${ }^{16,17}$ was used to confirm the proportional odds assumption for ordered logistic regression. We also used weighted logistic regression to assess the patient's perceptions as to whether their doctors find out about what their health concerns were.

\section{RESULTS}

Survey respondents who received health care in the past 12 months were asked to rate the quality of care they received 
( 1 = poor, 2 = fair, 3 = good, 4 = excellent). Overall, those who were insured gave significantly higher ratings of excellent/ good $(81 \%$ vs. $71 \%)$ compared to those who were uninsured (Table 1). Insured persons who had a usual source of health care gave significantly higher ratings than those who were uninsured ( $82 \%$ vs. $74 \%$ ). Similarly, insured respondents who had no usual source of health care gave significantly higher ratings of perceived quality of care compared to uninsured respondents with no usual source of health care $(73 \%$ vs. 64\%). Although not shown in Table 1, our analysis showed that insurance coverage is highly associated with the length of stay in the United States $(P<.05)$. Approximately $<50 \%$ of those who have lived in the United States for $\leq 10$ years have health insurance, whereas $>80 \%$ of those who have lived $>30$ years in the United States have insurance coverage.

In terms of demographic characteristics, insured respondents gave significantly higher ratings of care. A test of trend for the education categories shows a significant gradient with a higher percentage of college graduates rating their care as excellent/good compared to those who did not graduate high school ( $87 \%$ vs. $77 \%)$. There were no significant differences in quality ratings for those aged $\geq 65$ years regardless of their health insurance status.

US-born and foreign-born citizens, as well as Latino permanent residents who have health insurance, gave higher ratings

Table 1. Perceived Quality of Care Ratings among the Insured vs. the Uninsured $(n=3545 t)$

\begin{tabular}{|c|c|c|}
\hline Population subgroup & $\begin{array}{l}\text { Excellent/Good } \\
\text { quality of care } \\
\text { among the } \\
\text { insured }\end{array}$ & $\begin{array}{l}\text { Excellent/Good } \\
\text { quality of care } \\
\text { among the } \\
\text { uninsured }\end{array}$ \\
\hline Total $^{*}$ & $81 \%$ & $71 \%$ \\
\hline $\begin{array}{l}\text { Have usual source of } \\
\text { health care* }\end{array}$ & $82 \%$ & $74 \%$ \\
\hline No usual source of health care* & $73 \%$ & $64 \%$ \\
\hline Females* & $83 \%$ & $77 \%$ \\
\hline Males* & $79 \%$ & $65 \%$ \\
\hline \multicolumn{3}{|l|}{ Education } \\
\hline$<$ High school graduate* & $77 \%$ & $70 \%$ \\
\hline High school graduate* & $80 \%$ & $72 \%$ \\
\hline Some college** & $84 \%$ & $72 \%$ \\
\hline College graduates ${ }^{* * \neq}$ & $87 \%$ & $75 \%$ \\
\hline \multicolumn{3}{|l|}{ Age Categories } \\
\hline Age 18 to $29^{*}$ & $78 \%$ & $70 \%$ \\
\hline Age 30 to $49^{*}$ & $81 \%$ & $73 \%$ \\
\hline Age 50 to $64^{*}, \mathrm{~s}$ & $84 \%$ & $70 \%$ \\
\hline Age 65 and up ${ }^{\S}$ & $84 \%$ & $85 \%$ \\
\hline \multicolumn{3}{|l|}{ Immigration Status } \\
\hline US-born* & $82 \%$ & $67 \%$ \\
\hline Foreign-born US citizens* & $80 \%$ & $68 \%$ \\
\hline Foreign-born legal residents* & $79 \%$ & $71 \%$ \\
\hline Undocumented ${ }^{\mid l}$ & $77 \%$ & $77 \%$ \\
\hline \multicolumn{3}{|l|}{ Country of Origin } \\
\hline Mexico* & $74 \%$ & $63 \%$ \\
\hline Puerto Rico* & $79 \%$ & $67 \%$ \\
\hline Cuba* & $82 \%$ & $66 \%$ \\
\hline Central/South American* & $76 \%$ & $60 \%$ \\
\hline
\end{tabular}

*Significant difference $(P<0.05)$ in quality of care between insured and uninsured group

${ }^{\dagger}$ Excluding those who did not receive any care in the past 12 months

${ }^{\ddagger}$ Significant difference $(P<0.05)$ in education compared to those who did not graduate high school

${ }^{\S}$ Significant difference in age $(P<0.05)$ compared to those in the 18 to 29 age category

1 I Significant difference $(P<0.05)$ with US-born (comparison group) compared to the uninsured. Eighty-two percent of insured USborn Latinos reported receiving excellent/good quality of care compared to $67 \%$ for uninsured US-born Latinos. Regardless of health insurance status, we found no significant difference in perceived quality ratings for the undocumented. We also examined the perceived quality of care ratings by country of origin for foreign-born citizens and residents, and found significantly higher quality of care for those who had health insurance.

The perceived quality of care ratings by specific chronic conditions are presented in Table 2. Among those with any chronic conditions, $81 \%$ of the insured received excellent/good quality of care compared to $61 \%$ of the uninsured. Among those insured with no chronic conditions, $85 \%$ reported receiving excellent/good quality of care compared to $69 \%$ for those who were uninsured with no chronic conditions. In examining the specific chronic conditions including diabetes, asthma, hypertension, arthritis, heart disease and depression, variations in excellent/good quality of care received across different chronic conditions were observed, however, the difference in quality of care received for those who were insured was significantly higher for all specific chronic conditions compared to those who were uninsured $(P<0.05)$.

To better understand the factors underlying the differences in quality of care ratings received, a multivariate ordered logistic regression model was used to examine the associations among various sociodemographic variables with the perceived quality of health care received (Table 3, model 1). In the model, we examined perceived quality of care received in the past year differences by country of origin, controlling for age, sex, insurance coverage, education, marital status, having one or more chronic conditions, age of arrival in the United States, and region of the country. Results from the model show that Mexicans (OR=0.80; 95\% CI, 0.64-0.99) and Central/South Americans (OR=0.72; 95\% CI, .57-.91) were less likely to report better quality of health care compared to US-born Latinos. It should be noted that language of interview was also included in a preliminary analysis and was not significant because it was confounded with Mexicans and Central/South Americans. It was ultimately dropped from Table 3. Older participants (aged 50 to 64 years and aged $\geq 65$ years) were more likely to report better quality of care. Females report receiving better quality of care $(\mathrm{OR}=1.35$; 95\% CI, 1.15-1.59) compared to males, and those with insurance coverage report better quality of care $(\mathrm{OR}=1.47$; $95 \% \mathrm{CI}, 1.22-1.76)$, as well as respondents with either some college $(\mathrm{OR}=1.43$; 95\% CI, 1.101.86) or college graduates $(\mathrm{OR}=1.65 ; 95 \% \mathrm{CI}, 1.26-2.14)$.

In Table 3 (model 2), we examined perceptions among patients about whether their doctors always determine their health concerns. Results from the model show that Mexicans (OR=0.59; 95\% CI, 0.38-0.93) and Central/South Americans $(\mathrm{OR}=0.62$; 95\% CI, 0.38-0.99) were less likely to report that their doctors find out about what their health concerns were. College graduates (OR=3.24; 95\% CI, 1.50-7.00) and those who have health insurance were more likely to report that their doctors find out what their health concerns were.

After demographic characteristics were adjusted in an ordered logistic regression, we analyzed the distribution of the quality of care ratings by insurance status (Fig. 1). Those who were uninsured gave significantly worse ratings than those who had health insurance. Fewer participants rated their perceived quality of care as "excellent," which was the 
Table 2. Perceived Quality of Care Ratings among Those with Chronic Conditions $(n=1067)$

\begin{tabular}{|c|c|c|}
\hline & $\begin{array}{l}\text { Excellent/Good } \\
\text { Quality of Care } \\
\text { among the } \\
\text { Insured }\end{array}$ & $\begin{array}{l}\text { Excellent/Good } \\
\text { Quality of Care } \\
\text { among the } \\
\text { Uninsured }\end{array}$ \\
\hline Any chronic condition* & $81 \%$ & $61 \%$ \\
\hline No chronic condition* & $85 \%$ & $69 \%$ \\
\hline \multicolumn{3}{|c|}{ Specific chronic conditions } \\
\hline Diabetes* & $84 \%$ & $78 \%$ \\
\hline Asthma* & $70 \%$ & $53 \%$ \\
\hline Hypertension* & $83 \%$ & $64 \%$ \\
\hline Arthritis* & $83 \%$ & $68 \%$ \\
\hline Heart disease* & $72 \%$ & $61 \%$ \\
\hline Depression* & $73 \%$ & $63 \%$ \\
\hline
\end{tabular}

*Significant difference $(P<0.05)$ in quality of care between those insured vs. uninsured

highest rating category $(25 \%$ for the uninsured vs. $33 \%$ for those insured). A similar pattern can also be seen for those who rated their care as fair or poor: those who were uninsured reported less favorable ratings compared to those who had insurance.

As a sensitivity analysis, we also examined the number of doctor visits by insurance status and the quality of care ratings associated with these visits (Fig. 2). In the figure, we illustrate that those who were insured had significantly more doctor visits at the three or more visit categories. Furthermore, when we cross-referenced the number of visits categories with perceived quality of care ratings in Table 4, those who were insured had significantly higher endorsements of 'excellent/ good' ratings across all of the number of doctor visit categories $(P<.05)$ compared to those who were uninsured. The highest ratings occur among the insured with the highest number of doctor visits. Insured respondents with eight or more visits in a year reported higher rates of excellent/good quality of care vs. the uninsured with a similar number of visits $(76.2 \%$ vs. $54.6 \%, P<.05$ ) (Table 4).

\section{DISCUSSION}

This study demonstrates that access to insurance for Latinos has a substantial effect on improving perceived quality of care, and this is especially true for people with chronic diseases and with high utilization of health care. However, these findings are also disconcerting for prospects of improving quality of care in the near term. Because un-insurance is disproportionately concentrated in foreign-born Latino adults, and a large proportion of this group does not have legal residence in the United States, ${ }^{18}$ the findings presented here suggest that disparities in the quality of care will continue for a significant fraction of the population. Latinos are also more likely not to be citizens even if they are legal residents, and are disproportionately concentrated below the federal poverty standard or marginally above it. $^{19-21}$

These factors have been shown to be associated with decreases in both access and quality. ${ }^{22}$ Finally, because family members are often eligible for different insurance programs (with different benefit coverage) for adult and minor family members, navigating the maze of providers with distinctive eligibility requirements can be extraordinarily confusing for

Table 3. Multivariate Models of Perceptions of Quality of Physician Care

\begin{tabular}{|c|c|c|c|c|c|c|}
\hline & \multicolumn{3}{|c|}{ Perceived quality of care (Model 1) } & \multicolumn{3}{|c|}{$\begin{array}{l}\text { Doctor always finds out what your health concerns } \\
\text { were (Model 2) }\end{array}$} \\
\hline & Odds ratios & Confidence & Intervals & Odds ratios & Confidence & Intervals \\
\hline \multicolumn{7}{|l|}{ Country of origin: } \\
\hline Mexican & $0.80^{*}$ & 0.64 & 0.99 & $0.59^{*}$ & 0.38 & 0.93 \\
\hline Cuban & 0.75 & 0.51 & 1.10 & 0.47 & 0.20 & 1.12 \\
\hline Cen/South American & $0.72 *$ & 0.57 & 0.91 & $0.62 *$ & 0.38 & 0.99 \\
\hline Other Latinos & 0.89 & 0.39 & 2.04 & 0.77 & 0.18 & 3.31 \\
\hline \multicolumn{7}{|l|}{ Age Categories: } \\
\hline Age 30 to 49 & 1.21 & 0.96 & 1.51 & 1.40 & 0.84 & 2.34 \\
\hline Age 50 to 64 & $1.37^{*}$ & 1.04 & 1.79 & 1.02 & 0.58 & 1.77 \\
\hline Age 65 \& up & $1.59^{*}$ & 1.13 & 2.23 & 0.63 & 0.33 & 1.20 \\
\hline \multicolumn{7}{|l|}{ Education: } \\
\hline High school graduate & 1.21 & 0.99 & 1.49 & 1.22 & 0.81 & 1.85 \\
\hline Some college & $1.43^{*}$ & 1.10 & 1.86 & 1.64 & 0.97 & 2.78 \\
\hline College graduates & $1.65^{*}$ & 1.26 & 2.14 & $3.24 *$ & 1.50 & 7.00 \\
\hline Females & $1.35^{*}$ & 1.15 & 1.59 & 1.36 & 0.95 & 1.94 \\
\hline Married & 1.16 & 0.92 & 1.48 & 1.16 & 0.63 & 2.11 \\
\hline Divorced/separated & 0.98 & 0.71 & 1.35 & 1.00 & 0.50 & 1.99 \\
\hline Have health insurance & $1.47^{*}$ & 1.22 & 1.76 & $1.61^{*}$ & 1.10 & 2.36 \\
\hline Chronic condition & 1.01 & 0.84 & 1.20 & 1.01 & 0.68 & 1.51 \\
\hline Age of arrival $<12$ yrs & 1.12 & 0.84 & 1.49 & 1.13 & 0.55 & 2.31 \\
\hline \multicolumn{7}{|l|}{ Region: } \\
\hline Northeast & 1.10 & 0.87 & 1.39 & 1.00 & 0.60 & 1.67 \\
\hline Midwest & 1.04 & 0.75 & 1.45 & 1.26 & 0.58 & 2.72 \\
\hline South & 1.18 & 0.97 & 1.44 & 0.99 & 0.66 & 1.47 \\
\hline
\end{tabular}

*Significant at $P<.05$

Note: The reference categories are: country of origin - US; Age - 18 to 29 yrs old; education - less than high school graduate; marital status - single/never married; region - Western region 


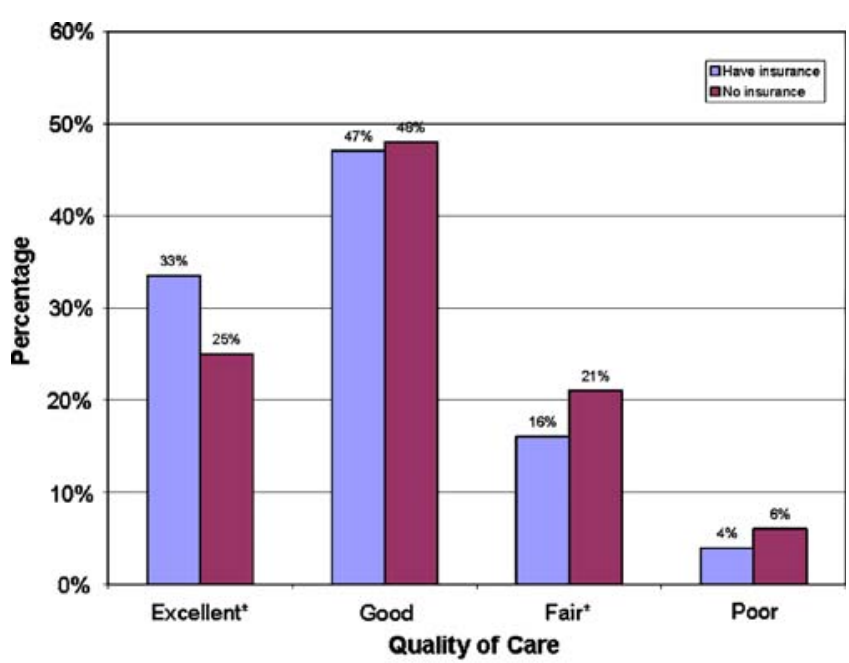

* $P<.05$, Significant differences between insured vs. uninsured

** Adjusted by age, sex, education, marital status, country of origin, chronic conditions, age of arrival and region

Figure 1. Quality of care received, by insurance status**.

low-literacy families with poor English language proficiency. ${ }^{19,23}$ The resulting perceptions of quality of care received under these circumstances may be diminished and is a likely explanation for the lower rates of quality of care reported among lower educated, younger and foreign-born Latinos ${ }^{24}$. An interesting finding is the deterioration reported in quality of care among high-need patients with no insurance, suggesting the weathering effects of long-term patient exposure to seeking treatment in the face of inadequate resources and fragmented coordination of care.

An important question in this study is precisely what does our perceived quality of care measure mean to the respondent? The use of questions that tap patient satisfaction with care among health care consumers has been a standard for



*Significant difference $(P<.05)$ in total number of visits in all categories except $1-2$ visits.

Figure 2. Health insurance coverage, by number of doctor visits*.
Table 4. Number of Doctor Visits by Perceived Quality of Care

\begin{tabular}{lll}
\hline \hline Number of visits & $\begin{array}{l}\text { Excellent/Good quality } \\
\text { of care, insured }\end{array}$ & $\begin{array}{l}\text { Excellent/Good quality } \\
\text { of care, uninsured }\end{array}$ \\
\hline 1 to 2 visits* & $84.8 \%$ & $74.1 \%$ \\
3 to 7 visits* & $83.4 \%$ & $63.5 \%$ \\
8 or more* & $76.2 \%$ & $54.6 \%$
\end{tabular}

*Significant difference $(P<0.05)$ in quality of care ratings between insured vs. uninsured

evaluation of health providers for many years. This project relied on a single item to assess interpersonal processes as is done in most research. The perceived quality of care measure may not always reflect objective factors underlying quality of care. Future research should examine this phenomenon with multiple item measures of interpersonal processes in order to provide more insight about determinants in the patientprovider nexus that influences perceptions of quality of care by Latinos. Assessments of quality of care must also take into account treatment outcomes and any potential behavior change associated with ratings of quality.

It is important to improve precision in measuring and understanding where other breakdowns may occur systematically in patient-centered care for Latino consumers, including fundamental elements such as communication, formation of adequate therapeutic alliance, payment and access barriers, and patient activation and readiness to navigate complex health care systems. Insights for improving patient care are optimized when using theoretical models or frameworks that also incorporate the social and cultural characteristics and expectations of Latino consumers and their families. A better understanding of the impact of lower perceptions of quality on behavior, i.e., treatment adherence, help-seeking and selfmanagement of disease, is a critical next step in research on quality of care.

This study has limitations. Respondents who were undocumented may not have provided accurate responses because of the associated social stigma and fear of detection. More visits to the doctor and the associated excellent/good quality of care ratings may not necessarily mean that patients are getting appropriate care since the type of services received may vary substantially and was not assessed in this study since treatment data were not available. Further research is needed to address these issues.

\section{CONCLUSION}

This study examined the association between perceived quality of care ratings and health insurance of a Latino population, using data from a national sample of Latinos collected in the Pew Hispanic Center/Robert Wood Johnson Foundation Latino Health Surveys (Waves 1 and 2) ${ }^{14}$ conducted between 2007 and 2008. The results conclusively demonstrated the consistent effects of health insurance for improving perceived quality of care in Latino patients. Using a logistic regression model, perceived quality of care was positively associated (and statistically significant) with higher educational attainment-especially being a college graduate, sex (female), being middle aged or older, and health insurance availability. Worse quality of 
care was predicted by Mexican or Central/South American nationality. Region of residence was not associated with perceived quality of care. The greatest distinction in consumer ratings was for the excellent category, where $33 \%$ of insured reported excellent care compared to only $25 \%$ of the uninsured. Perceived quality of care differed most widely among the insured and uninsured who reported high intensity service use that presumably reflected more severe medical conditions in this patient group. Coupled with the knowledge and understanding of the effects of health insurance coverage presented in this study, additional research could help to develop programs that improve quality of care among Latino populations.

Acknowledgments: This project was supported by the Network for Multicultural Research on Health and Healthcare, Dept. of Family Medicine-UCLA David Geffen School of Medicine, funded by the Robert Wood Johnson Foundation.

Conflict of Interest: None disclosed.

Corresponding Author: William A. Vega, PhD; UCLA Department of Family Medicine, 10880 Wilshire Blvd. \#1800, Los Angeles, CA 90024, USA (e-mail: WVega@mednet.ucla.edu).

\section{REFERENCES}

1. Blendon RJ, Buhr T, Cassidy EF, et al. Disparities in health: perspectives of a multi-ethnic, multi-racial America. Health Affairs. 2007;26:1437-47.

2. Schoen C, Osborn R, How SK, Doty MM, Peugh J. In chronic condition: experiences of patients with complex health care needs, in eight countries, 2008. Health Affairs. 2008;1:1-16.

3. Kaiser Commission on Medicaid and the Uninsured. Health insurance coverage and access to care among Latinos. Washington, DC: Kaiser Family Foundation; 2000.

4. Ross JS, Bradely EH, Busch SH. Use of health care services by lower income and higher-income uninsured adults. JAMA. 2006;295:2027-36.

5. Livingston G, Minushkin S, Cohn, D. Hispanics and Health Care in the United States: access, Information, and Knowledge. A Joint Pew Hispanic Center and Robert Wood Johnson Foundation Research Report. Washington, DC: Pew Hispanic Center \& Robert Wood Johnson Foundation. 2008.

6. Cleary PD, Edgman-Levitan S. Health care quality. Incorporating consumer perspectives. JAMA. 1997;278:1608-12.
7. Cleary PD. The increasing importance of patient surveys. BMJ. 1999;319:720-1.

8. Agency for Health Care Research and Quality. 2007 National Healthcare Quality \& Disparities Reports. Washington, DC: US Department of Health and Human Services; 2007.

9. Kaiser Family Foundation \& Pew Hispanic Center. Health Care Experiences - 2002. A National Survey of Latinos. Available at: http:// pewhispanic.org/files/reports/25.pdf. Last accessed: July 14, 2009.

10. Alegria M, Takeuchi D. National Latino and Asian American Study (NLAAS), 2002-2003. Available at http://www.multiculturalmental health.org/nlaas.asp. Last accessed: July 14, 2009.

11. Vega WA, Kolody B, Aguilar-Gaxiola S, Catalano R. Gaps in service utilization by Mexican Americans with mental health problems. Am J Psychiatry. 1999;156:928-34.

12. Institute of Medicine. Crossing the quality chasm: The IOM Health Care Quality Initiative. Washington, DC: National Academies Press; 2006.

13. McGuire TG, Alegria M, Cook BL, Wells KB, Zaslavsky AM. Implementing the Institute of Medicine definition of disparities: An application to mental health care. Health Serv Res. 2006;41:1979-2005.

14. PewResearchCenter Project. Hispanic and Health Care in the United States: Access, Information and Knowledge. Washington, DC: A Joint Pew Hispanic Center and Robert Wood Johnson Foundation Research Report. August, 2008.

15. Rao JNK, Scott JA. On chi-squared tests for multiway contingency tables with cell proportions estimated from survey data. Ann Statist. 1984;12:46-60.

16. Holtbrugge W, Schumacher M. A comparison of regression models for the analysis of ordered categorical data. Appl Stat. 1991;40:249-59.

17. Ananth CV, Kleinbaum DG. Regression models for ordinal responses: a review of methods and applications. Int $\mathrm{J}$ Epidemiol. 1997;26: 1323-33.

18. Shah NS, Carrasquillo o. Twelve-year trends in health insurance coverage among Latinos, by subgroup and immigration status. Health Affairs. 2006;25:1612-9.

19. Doty MM. Hispanic patients' double burden: Lack of health insurance and limited english. Report \#592. New York, NY: The Commonwealth Fund; 2003.

20. DeNavas-Walt C, Proctor BD, Smith JC. Income, poverty, and health insurance coverage in the United States: 2007. Washington, DC: US Census Bureau; 2007.

21. Bustamante AV, Ojeda G, Castaneda X. Willingness to pay for crossborder health insurance between the United States and Mexico. Health Affairs. 2008;1:168-78.

22. Ku L, Matani S. Left out: Immigrants' access to health care and insurance. Health Affairs. 2001;20:247-56.

23. Olson LM, Tang AA, Newacheck PW. Children in the United States with discontinuous health insurance coverage. New Engl $\mathrm{J}$ Med. 2005;353:382-91.

24. Derose KP, Escarce JJ, Lurie N. Immigrants and health care: Sources of vulnerability. Health Affairs. 2007;26:1258-68. 